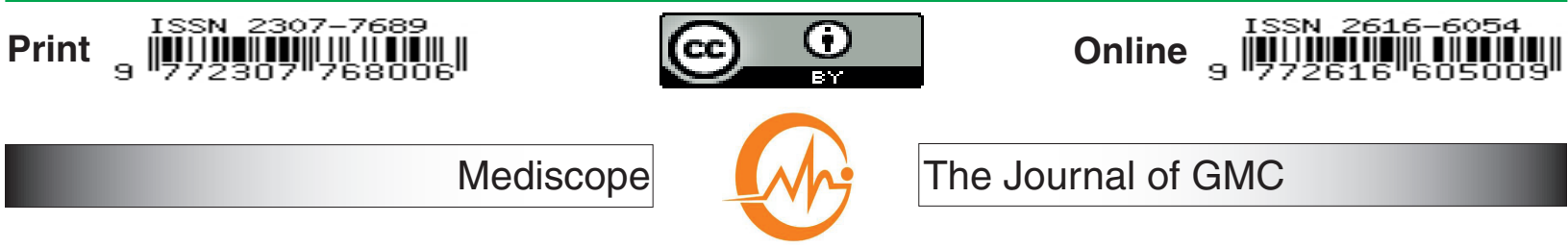

\title{
Incidence of heart failure in patients of acute ST elevation myocardial infarction with impaired renal function
}

\author{
MMA Shamim ${ }^{1 凶}$, ME Haque ${ }^{2}$, I Chowdhury ${ }^{3}$, A Debnath $^{4}$, S Arefin ${ }^{5}$, MA Hamja ${ }^{6}$
}

\begin{abstract}
Ischemic heart disease is a common cardiac disorder and significant cause of mortality and morbidity worldwide. Effective risk stratification is integral to the management of patients with acute coronary syndromes and associated chronic kidney disease may adversely affect acute ST elevation myocardial infarction (STEMI) outcome. This prospective study was conducted in the Department of Cardiology, Chittagong Medical College Hospital after approval of the protocol for the study with duration of one year. For these purpose 100 patients of STEMI diagnosed by clinical, biochemical and ECG criteria were included in the study. After getting serum creatinine level, estimated glomerular filtration rate was calculated and if it is $<60 \mathrm{ml} / \mathrm{min}$ then the patient was selected for the study. Among the 100 patients inferior Ml was $34 \%$, anterior $\mathrm{MI}$ was $20 \%$, extensive anterior $\mathrm{MI}$ was $12 \%$, antero-septal MI was $18 \%$, infero-lateral MI was $10 \%$, lateral $\mathrm{MI}$ was $2 \%$, high lateral $\mathrm{Ml}$ was $3 \%$ and antero-inferior was $1 \%$. Of these patients heart failure was found in $21 \%$ of the patients. The association between incidence of heart failure patients and eGFR was statistically significant $(p<0.05)$. From this study, it was concluded that impaired renal function among MI patients plays a role for an adverse outcome. Early detection of renal impairment is necessary to avoid increased morbidity and mortality. Key words: STEMI, renal impairment, heart failure.
\end{abstract}

\section{Introduction}

Coronary heart disease is a worldwide health epidemic. Worldwide, $30 \%$ of all deaths can be attributed to cardiovascular disease of which more than half are caused by coronary heart disease. Globally of those dying from cardiovascular disease, $80 \%$ are from developing countries. ${ }^{1}$ In 2001, it was estimated that worldwide coronary artery disease was responsible for $11.8 \%$ of all deaths in low income countries. ${ }^{2}$
Incidence of coronary artery disease in Bangladesh has increased from 3.3 per thousand to 14 per thousand from the year 1975 to $1985 .{ }^{3}$ Acute ST elevation myocardial infarction (STEMI) is defined by at least two of the followings in which typical ECG changes is a must and any one either typical chest pain of cardiac origin or significantly raised troponin-I level. ${ }^{4}$

In STEMI cigarette smoking, male gender

\footnotetext{
1. MMA Shamim, MBBS, MD (Cardiology), Assistant Professor, Department of Cardiology, Gazi Medical College, Khulna. Email: drmmshamim76@gmail.com

2. ME Haque, MBBS, MCPS (Medicine), DCard, Professor, Department of Cardiology, Gazi Medical College, Khulna

3. I Chowdhury, Associate Professor, Department of Cardiology, Gazi Medical College, Khulna

4. A Debnath, MBBS, Medical Officer, Gazi Medical College Hospital, Khulna

5. S Arefin, MBBS, Medical Officer, Gazi Medical College Hospital, Khulna

6. MA Hamja, MBBS, Medical Officer, Gazi Medical College Hospital, Khulna
} 
and a family history of cardiovascular and renal disease are associated with adverse prognosis in young patients, whereas dyslipidemia, hypertension and diabetes mellitus are associated with adverse prognosis in the elderly. ${ }^{5}$ Impaired renal function is manifested by decreased estimated glomerular filtration rate (eGFR). Decreased eGFR is measured by increased serum creatinine or more preciously by reduced creatinine clearance $(<60 \mathrm{ml} / \mathrm{min})$. It is an independent risk factor for coronary artery disease (CAD) outcome. $^{6-7}$ Mild renal impairment is associated with an increased risk of CAD and stroke, suggesting that cardiovascular disease may develop early in the course of renal dysfunction. ${ }^{8-9}$

It is a time demand for a study to determine the incidence of heart failure in patients of acute STEMI with impaired renal function. Therefore, the aim of this study was to determine the incidence of heart failure in patients of acute STEMI with impaired renal function.

\section{Materials and Method}

This prospective observational study was conducted at Chittagong Medical College Hospital $(\mathrm{CMCH})$ during a period of one year from January 2014 to December 2014 after the approval of Ethical Review Committee. For this purpose 100 patients of acute STEMI with impaired renal function were included in this study.

\section{Inclusion criteria}

Patient's of acute STEMI within twelve hours after the onset of chest pain who were eligible for thrombolysis, eGFR $<60 \mathrm{ml} / \mathrm{min}$ (Cockcroft-Gault formula), and voluntarily gave consent to participate in the study.

\section{Exclusion criteria}

Non-STEMI, patients who are not eligible for thrombolysis, STEMI with previous history of MI, STEMI patients with history of vulvular heart disease, cardiomyopathy, congestive heart failure, patients with STEMI presenting with VT or VF, previous known case of diabetic nephropathy or known case of chronic kidney disease.

\section{Operational definitions}

STEMI was at least a $2 \mathrm{~mm}$ ST segment elevation in at least 2 contiguous leads in the precordium or at least $1 \mathrm{~mm}$ ST segment elevation in 2 contiguous limb leads. Renal impairment defines that eGFR $<60$ $\mathrm{ml} / \mathrm{min} / 1.73 \mathrm{~m}^{2}$.

\section{Informed consent}

A patient with diagnosed case of $\mathrm{Ml}$ or his/her legal guardian was thoroughly informed about the aims, objectives and detailed procedure of the study before examination. S/he was encouraged for voluntary participation and allowed freedom to withdraw from the study whenever s/he liked even after participation.

\section{Procedure of data collection and analysis} From all eligible subjects after getting consent, clinical history was taken and clinical examination was done to elicit findings related to MI. Related investigations like blood sugar and serum creatinine were done. Blood was collected within two hours after admission of the patient in the hospital. If the patients' calculated eGFR is $<60$ $\mathrm{ml} / \mathrm{min}$ and ECG criteria confirms the acute STEMI then s/he was included in the study as a case. The patients were followed up till discharge with special attention to serum creatinine and development of other complications. The researchers did not influence the ongoing hospital treatment. The endpoint of the study was sudden cardiac death or rise of serum creatinine double of the baseline value. All relevant data were noted in the pre tested data sheet. All data were checked and rechecked to avoid any error. All investigations were done in the Department of Biochemistry, $\mathrm{CMCH}$, and if not possible, in the standard laboratories of Chittagong.

Data were processed and analyzed by using a computer based software Statistical Package for Social Science 19. Discrete or qualitative variables were analyzed by Chi-square test and continuous variables by $t$-test. The $p$ value $<0.05$ was considered as statistically significant.

\section{Results}

Most of the patients (67\%) were in between 41-60 years (Table 1). Among the patients, 77 were male and 23 were female (Table 2). Among the heart failure patients raised jugu- 
Table 1. Age distribution of the patients, $n=100$

\begin{tabular}{lrr}
\hline Age in years & Frequency & \% \\
\hline$<40$ & 14 & 14.0 \\
$41-50$ & 32 & 32.0 \\
$51-60$ & 35 & 35.0 \\
$61-70$ & 19 & 19.0 \\
\hline
\end{tabular}

n, number; mean $\pm \mathrm{SD}$ was $52.8 \pm 8.4$ years.

Table 2. Gender distribution of the patients, $n=100$

\begin{tabular}{lrr}
\hline Gender & Frequency & \% \\
\hline Male & 77 & 77.0 \\
Female & 23 & 23.0 \\
\hline
\end{tabular}

Table 3. Examination findings

\begin{tabular}{lrr}
\hline Clinical examinations & Frequency & $\mathbf{\%}$ \\
\hline Raised jugular venous pressure & 12 & 12.0 \\
Gallop rhythm & 10 & 10.0 \\
Basal crepitations & 21 & 21.0 \\
\hline
\end{tabular}

Table 4: Distribution of investigation findings, $n=100$

\begin{tabular}{lr}
\hline Investigations & Mean \pm SD \\
\hline Left ventricular ejection fraction, \% & $50.8 \pm 10.0$ \\
Random blood sugar, mg/dl & $222.8 \pm 72.2$ \\
Low-density lipoprotein-cholesterol & $210.0 \pm 23.8$ \\
Serum creatinine & $1.6 \pm 0.4$ \\
\hline
\end{tabular}

Table 5. Types of myocardial infarction among the study population

\begin{tabular}{lrr}
\hline Types & Frequency & $\mathbf{\%}$ \\
\hline Inferior & 34 & 34.0 \\
Anterior & 20 & 20.0 \\
Extensive anterior & 12 & 12.0 \\
Antero-septal & 18 & 18.0 \\
Infero-lateral & 10 & 10.0 \\
Lateral & 2 & 2.0 \\
High lateral & 3 & 3.0 \\
Antero-inferior & 1 & 1.0 \\
\hline Total & 100 & 100.0 \\
\hline
\end{tabular}

Table 6. Incidence of heart failure patients stratified by eGFR, $n=100$

\begin{tabular}{|c|c|c|c|c|c|c|c|}
\hline & & & FR, & $\min$ & & & $p$ value \\
\hline & $\begin{array}{r}60 \\
(n=)\end{array}$ & & $\begin{array}{r}30 \\
(n=\end{array}$ & & & & \\
\hline & $\mathbf{n}$ & $\%$ & $\mathbf{n}$ & $\%$ & $\mathbf{n}$ & $\%$ & \\
\hline Heart failure, $n=21$ & 11 & 15.5 & 6 & 27.3 & 4 & 57.1 & 0.026 \\
\hline
\end{tabular}

n, number; eGFR, estimated glomerular filtration rate. 
lar venous pressure was found in $12 \%$, gallop rhythm in $10 \%$ and basal crepitation in 21\% (Table 3).

The common risk factors were hypertension, dyslipidemia, smoking and diabetes mellitus (Table 4). Of these patients, the mean \pm SD of left ventricular ejection fraction (\%) was found $50.8 \pm 10.0$, random blood sugar was found in $222.8 \pm 72.2$, serum creatinine was found 1.6 \pm 0.4 . Among the patients, the inferior MI was $34 \%$, anterior MI $20 \%$, extensive anterior $\mathrm{Ml} 12 \%$, antero-septal $\mathrm{Ml} 18 \%$, infero-lateral $\mathrm{MI} 10 \%$, lateral $\mathrm{MI} 2 \%$, high lateral MI 3\%, antero-inferior MI 1\% (Table 5).

The incidence of heart failure was $21 \%$ (Table 6). Out of 21 heart failure patients, eGFR was $60-30 \mathrm{ml} / \mathrm{min}$ in 11 patients, $30-15 \mathrm{ml} / \mathrm{min}$ in 6 patients, $<15 \mathrm{ml} / \mathrm{min}$ in 4 patients (Table 6). The association between incidence of heart failure patients and eGFR was statistically significant $(p<0.05)$.

\section{Discussion}

Acute myocardial infarction is one of the major health problems all over the world and the coronary artery thrombosis is the leading cause of it. ${ }^{10}$ In the developing country like Bangladesh, urbanization is taking place at a rapid pace that is responsible for change in the lifestyle which adversely affects the metabolism thereby causing a large increase in the number of diabetic patients. ${ }^{11}$

In the present study, among 100 patients male was $77 \%$ and female $23 \%$. Male to female ratio was 3.34:1. A higher prevalence of ischemic heart disease in male than female has been reported in a study from England. ${ }^{11}$ Thus the present results are in agreement that male population is more prone to STEMI which may be linked to genetic/ hormonal difference. The present study showed among the 100 patients most of the patients were in age of 51-60 years $(35 \%)$ next to which in $41-50$ years $(32 \%)$. The mean \pm SD of age was $52.8 \pm 8.4$ years.

Regarding the evaluation of risk factors of STEMI, hypertension was found in $61 \%$, smoking in $52 \%$, dyslipidemia in $78 \%$, diabe- tes mellitus in $31 \%$, sedentary life style in $23 \%$, obesity in $23 \%$ of total patients and family history of ischemic heart disease was found in $24 \%$ of patients. The results of the present study with reference to risk factors were similar to those published earlier that type 2 diabetic patients were more hypertensive than non diabetic. ${ }^{12}$ It was reported that $48 \%$ patients were found hypertensive in the diabetic group whereas only $36 \%$ patients were found hypertensive in non diabetic group. All of the above findings are consistent with the earlier study. ${ }^{13}$

Of the 100 patients, inferior $\mathrm{MI}$ was $34 \%$, anterior MI $20 \%$, extensive anterior MI $18 \%$, antero-septal MI $12 \%$, infero-lateral MI $10 \%$, lateral $\mathrm{MI} 2 \%$, high lateral $\mathrm{MI} 3 \%$ and antero-inferior $1 \%$. The present study found non-significant difference in the site of infarction among all patients. Inferior and anterior infarctions were common. In some studies lateral infarction was found common in diabetic group. ${ }^{14}$ However, the present study was not similar which may be due to the small size of the study population.

Regarding analysis of complications and outcome, the mean $\pm S D$ of hospital stay of the study patients was $4.5 \pm 0.8$ days. Left ventricular ejection fraction (\%) was found in $50.8 \pm 10.0$ and random blood sugar was found in $222.8 \pm 72.2 \mathrm{mg} / \mathrm{dll}$. Among the 100 patients, heart failure was found in $21 \%$. These findings are as expected from the patients with STEMI. ${ }^{15}$

Regarding eGFR and different complications, more were found with low eGFR. The association between incidence of heart failure patients and eGFR was statistically significant. We have shown that in patients admitted with STEMI and across each STEMI grouping, creatinine clearance was an important independent predictor of hospital mortality. In our study, 4 cases died with low eGFR. A $10 \mathrm{ml} / \mathrm{min}$ decrease in creatinine clearance had the same adverse impact on hospital death rates as a 10 year increase in age. Increased renal dysfunction was observed more often in elderly (age >65 
years) and female patients. It is well known that renal function decreases with age, and women are considerably older than men when they are admitted with an STEMI, which may partially explain the predominance of women with reduced renal function. ${ }^{11}$

Increased creatinine concentrations are common in older patients and are independently associated with an increased risk of death, cardiovascular disease, and congestive heart failure. It can be said that the increased risk of death begins with mildly elevated concentrations of serum creatinine.

\section{Conclusion}

From the present study findings, it can be concluded that increased incidence of heart failure occurs among $\mathrm{Ml}$ patients with impaired renal function. Early detection of renal impairment is necessary to avoid increased morbidity and mortality.

\section{References}

1. Kim MC, Kini AS, Fuster V. Definitions of acute coronary syndromes. In: Fuster V, O'Rourke RA, Walsh RA, Poole-Wilson P. Eds. Hurst's the Heart. $12^{\text {th }}$ ed. New York, USA: McGraw Hill; 2008.

2. Yang EH, Gersh BJ, O'Rourke RA. ST segment elevation myocardial infarction. In: Fuster V, O'Rourke RA, Walsh RA, Poole-Wilson P. Eds. Hurst's the Heart. 12 $2^{\text {th }}$ ed. New York, USA: McGraw Hill; 2008.

3. Malik A. Congenital and acquired heart disease: a survey of 7062 person. Bangladesh Med Res Bull 1976;11:115-9.

4. Kim MC, Kini AS, Fuster V. Definitions of acute coronary syndromes: non-ST elevation myocardial infarction. In: Fuster V, O'Rourke RA, Walsh RA, Poole-Wilson P. Eds. Hurst's the Heart. 12 $2^{\text {th }}$ ed. New York, USA: McGraw Hill; 2008.

5. Abbott JD, Ahmed HN, Vlachos HA, Selzer F, Williams DO. Comparison of outcome in patients with ST-elevation versus non-STelevation acute myocardial infarction treated with percutaneous coronary intervention. Am J Cardiol 2007;100:193-5.

\section{Suggestion for citation of the above:}

Shamim MMA, Haque ME, Chowdhury I, Debnath A, Arefin S, Hamja MA. Incidence of heart failure in patients of acute ST elevation myocardial infarction with impaired renal function. Mediscope 2019;6(1):7-11.
6. Wannamethee SG, Shaper AG, Perry IJ. Serum creatinine concentration and risk of cardiovascular disease: a possible marker for increased risk of stroke. Stroke 1997;28:557-63.

7. Alcorn HG, Wolfson SKJr, Sutton-Tyrrell K. Risk factors for abdominal aortic aneurysms in older adults enrolled in the cardiovascular health study. Arterioscler Thromb Vasc Biol 1996;16:963-70.

8. Pahor M, Shorr RI, Somes GW. Diureticbased treatment and cardiovascular events in patients with mild renal dysfunction enrolled in the systolic hypertension in the elderly program. Arch Intern Med 1998;158:1340-5.

9. Culleton BF, Larson MG, Wilson PW. Cardiovascular disease and mortality in a community-based cohort with mild renal insufficiency. Kidney Int 1999;56:2214-9.

10.Ramachandan A, Snehalata C, Satyavani K, Vijay V. Impaired fasting glucose and impaired glucose tolerance in urban population in India. Diabet Med 2003;20(3):220-4.

11.Culie V. Acute myocardial infarction: differing preinfraction and clinical features according to infarct site and gender. Int $\mathrm{J}$ Cardiol 2003;90(2-3):189-96.

12.Chowdhury MAR, Hossain AKMM. A comparative study on the effects of streptokinase between diabetic and non-diabetic myocardial infarction patients. Bangladesh $\mathrm{J}$ Pharmacol 2008;3:1-7.

13.Antopinto JJ, Fox KAA, Goldberg RJ, et al. on behalf of the GRACE Investigators. Creatinine clearance and adverse hospital outcomes in patients with acute coronary syndromes: findings from the global registry of acute coronary events (GRACE). Heart 2003;89:1003-8.

14. Thiele H. Comparison of pre-hospital combination fibrinolysis plus facilitated percutaneous coronary intervention in acute myocardial infarction. Eur Heart J 2005;26:1956-63.

15.Kim MC, Kini AS, Fuster V. Definitions of acute coronary syndromes: ST-segment elevation myocardial infarction. In: Fuster V, O'Rourke RA, Walsh RA, Poole-Wilson P. Eds. Hurst's the Heart. $12^{\text {th }}$ ed. New York, USA: McGraw Hill; 2008. 